\title{
Methylene blue alters retention of inhibitory avoidance responses
}

\author{
JOE L. MARTINEZ, JR., ROBERT A. JENSEN, BEATRIZ J. VASQUEZ \\ TERESA McGUINNESS, and JAMES L. McGAUGH \\ Department of Psychobiology, School of Biological Sciences, University of California \\ Irvine, California 92717
}

\begin{abstract}
These experiments examined the effects of methylene blue on retention, by rats and mice, of an inhibitory avoidance response. The studies using mice investigated the effects of graded doses of methylene blue administered shortly before or after training. A $500-\mathrm{mg} / \mathrm{kg}$ dose impaired retention in mice (tested 3 days after training) if administered $15 \mathrm{~min}$, but not 30 or 5 min, prior to training. Further studies with rats indicated that retention was enhanced by a low dose $(1.0 \mathrm{mg} / \mathrm{kg}$ ) administered immediately after training (tested 1 day after training). Retention in rats was not affected by a $1.0-\mathrm{mg} / \mathrm{kg}$ dose given $15 \mathrm{~min}$ before training, $6 \mathrm{~h}$ after training, or $15 \mathrm{~min}$ before testing. These results are interpreted in the light of methylene blue's actions on blood hemoglobin and carbohydrate metabolism.
\end{abstract}

These studies examined the effects of methylene blue (MB) on memory storage processes. We selected MB because it has two distinct actions on blood hemoglobin $(\mathrm{Hb})$, depending on dose. In low doses, MB converts methemoglobin $(\mathrm{MHb})$ to $\mathrm{Hb}$, and in high doses, it does the reverse (Harvey, 1975). It is thought that this dual action of MB occurs in the following way. When administered in low doses, $\mathrm{MB}$ acts as an electron acceptor in the transfer of electrons from reduced pyridine nucleotides to $\mathrm{MHb} . \mathrm{MB}$ is reduced to leukomethylene blue, which in turn reduces $\mathrm{MHb}$ to $\mathrm{Hb}$ nonenzymatically. In addition, as electrons are transferred from nicotinamide adenine dinucleotide phosphate (NADPH) to $\mathrm{MB}$, there is an increase in glucose oxidation via the pentose phosphate pathway as a result of oxidation of NADPH (Smith \& Thron, 1972). In high doses, MB oxidizes the ferrous iron of reduced $\mathrm{Hb}$ to the ferric form and produces $\mathrm{MHb}$ (Harvey, 1975).

It is well known that hypoxia is effective in producing amnesia in the type of inhibitory avoidance task used in this study (Anderson \& Robichaud, 1975). It was thought that, in high doses, MB should produce amnesia because of the hypoxia produced by conversion of $\mathrm{Hb}$ to $\mathrm{MHb}$. In low doses, MB might be expected to facilitate retention by converting $\mathrm{MHb}$ to $\mathrm{Hb}$, thereby increasing the oxygen-carrying capacity of erythrocytes and by stimulating the pentose phosphate shunt, an important pathway for central glucose metabolism, particularly during stress (Himwich, 1976; Maker, Clarke, \& Lajtha, 1976).

This research was supported by Research Grants MH 12526 (J.L.McG.), Postdoctoral Fellowships MH 05249 (J.L.M.Jr.), and MH 05358 (R.A.J.) from the U.S. Public Health Service, BNS 76-17370 from the National Science Foundation (J.L.McG.), and a grant from the McKnight Foundation (J.L.McG.). We thank Mr. Scott Herness for his technical assistance.

\section{MATERIALS AND METHODS}

The subjects were male Swiss-Webster mice (22-36 g) and male Fischer 344 rats $(112-230 \mathrm{~g})$. The mice were housed eight to a cage, and the rats were housed individually. The animals were maintained on a standard light-dark cycle (LD 12:12, lights on at 7:00 a.m.). Food and water were available ad lib. Following adaptation to laboratory conditions for at least 5 days, the animals were trained in a one-trial inhibitory avoidance step-through task. Training and testing were performed between the hours of 1:00 and 5:00 p.m.

The training apparatus used for the mice consisted of a small transparent start compartment separated from a larger black compartment by a guillotine door (Haycock \& McGaugh, 1973; Jarvik \& Kopp, 1967). The mouse was placed in the illuminated start compartment. Five seconds later, the guillotine door was raised and the animal was allowed to step through into the larger dark compartment. When the mouse traveled $8.4 \mathrm{~cm}$ from the door, it activated a touch-sensitive circuit stopping a timer that recorded the entrance latency and delivered a squarewave $350-\mu \mathrm{A}$ constant-current footshock $(700 \mu \mathrm{A}$ zero-to-peak, on $50 \%$ of the time) through two metal floor plates. Shock was terminated when the mouse escaped back into the start compartment. Retention tests were given 3 days following training. The retention testing procedure was identical to training, except that no shock was administered. An animal was allowed to remain in the start compartment for $600 \mathrm{sec}$ (ceiling score), after which it was removed and assigned a score of 600 .

Training for the rats consisted of placing them in a white illuminated start compartment (Martinez, MoGaugh, Hanes, \& Lacob, 1977) facing away from a vertical sliding door. Upon turning around, the door to the larger dark shock compartment was lowered and the rats were allowed to step through. After all four paws contacted the two metal floor plates, the door was closed and an inescapable $500-\mu \mathrm{A} / .5 \mathrm{sec}$ footshock was delivered to the animal. The level of the constant-current sinusoidal footshock (Lafayette Instrument $\mathrm{Co}$.) was determined by the root mean square of the sine wave. On a retention test given $24 \mathrm{~h}$ following training, the rat was placed in the start compartment as in training. If the rat failed to step through to the dark side within $600 \mathrm{sec}$, it was removed from the apparatus.

Methylene blue (Sigma; 3,9-bisdimethylaminophenazothonium) was dissolved in deionized water and injected IP into the animals. Control injections consisted of $0.9 \% \mathrm{NaCl}$. The data 
were analyzed by multiple Mann-Whitney U-test comparisons. The use of cutoff scores in the retention test produces a truncated distribution of retention scores that are more appropriately analyzed by nonparametric techniques.

\section{EXPERIMENT 1}

\section{Procedures}

In this experiment, mice were injected with either saline $(\mathrm{n}=26)$ or one of several doses $(\mathrm{mg} / \mathrm{kg})$ of $\mathrm{MB} 30 \mathrm{~min}$ prior to training: $.05(n=26), .5(n=24), 5.0(n=24)$, or $50.0(n=18)$. Additional animals received either saline $(n=22)$ or one of several doses $(\mathrm{mg} / \mathrm{kg})$ of $\mathrm{MB}$ immediately following training: $.05(n=22), .5(n=24), 5.0(n=24)$, or $50.0(n=17)$. Training and testing were conducted as described in the Materials and Methods section.

\section{Results}

Analysis of the retention latencies of the groups given saline either 30 min before training or immediately after training, by a Mann-Whitney U test, indicated that they did not significantly differ from each other $(z=.60)$. Consequently, the two saline groups were pooled for all further analysis. Mann-Whitney U-test comparisons revealed no significant differences among any of the groups receiving MB. However, the mice given $50.0 \mathrm{mg} / \mathrm{kg} \mathrm{MB} 30 \mathrm{~min}$ before training exhibited a retention deficit that approached significance $(U=542.5$, $\mathrm{z}=1.59, \mathrm{p}=.11$, two-tailed test). Also, mice given $.05 \mathrm{mg} / \mathrm{kg}$ MB immediately following training exhibited retrograde enhancement of learning that approached significance $(\mathrm{U}=405.0, \mathrm{z}=1.56, \mathrm{p}=.12)$.

\section{EXPERIMENT 2}

\section{Procedures}

Because the results of Experiment 1 indicated that MB may be affecting acquisition of the response, we decided to examine more closely the temporal relationship between drug administration and training with the high dose of MB. To this end, $50.0 \mathrm{mg} / \mathrm{kg}$ were administered to mice either $15 \mathrm{~min}(\mathrm{n}=27)$ or 5 min $(n=29)$ before training. Two saline control groups were also injected either $15 \mathrm{~min}(\mathrm{n}=32)$ or $5 \mathrm{~min}(\mathrm{n}=31)$ before training. All other training and testing procedures were as in Experiment 1 .

\section{Results}

As before, analysis of the retention latencies of the two saline-injected control groups (Mann-Whitney $U$ test) indicated that they did not significantly differ from each other $(\mathrm{z}=.54)$; thus, saline control animals were again pooled for all further comparisons.

The median retention latencies of the mice given $50.0 \mathrm{mg} / \mathrm{kg} \mathrm{MB}$ may be seen in Figure 1. A significant anterograde amnesia was observed if the MB was administered $15 \mathrm{~min}$ before training $(\mathrm{U}=670.5, \mathrm{z}=2.26$, $\mathrm{p}=.0238$, but not $5 \mathrm{~min}$ before training $(\mathrm{U}=815.5$, $\mathrm{z}=.31, \mathrm{p}>.05)$. A one-way analysis of variance of the initial entrance latencies indicated that MB did not affect these scores $[F(2,119)=.59, p>.05]$. The mean entrance latencies for the three groups of experimental
Swiss - Webster Mice

Experiment II

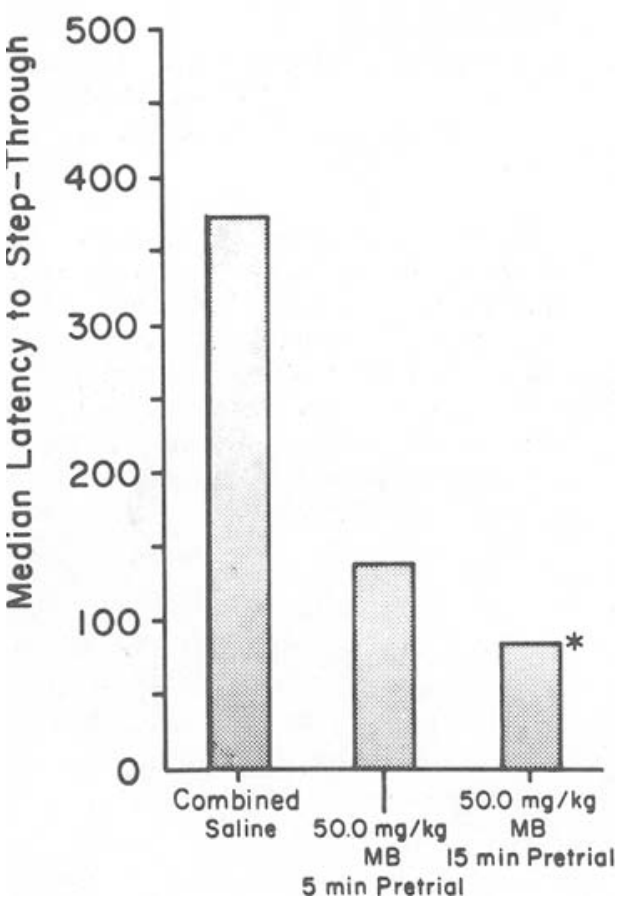

Figure 1. This figure demonstrates that a high dose of methylene blue (MB), $50 \mathrm{mg} / \mathrm{kg}$, produces amnesia only if it is given $15 \mathrm{~min}$ $(p=.02)$ before training in an inhibitory avoidance task. Median latency to step through is represented on the y-axis in seconds.

animals on training day were: combined saline $=$ $8.53 \mathrm{sec} ; 50 \mathrm{mg} / \mathrm{kg}, 15 \mathrm{~min}$ before training = 9.77; $50 \mathrm{mg} / \mathrm{kg}, 5 \mathrm{~min}$ before training $=5.75$.

\section{EXPERIMENT 3}

\section{Procedures}

Having demonstrated that MB produces anterograde amnesia in mice if it is given at the appropriate time prior to training, we decided to investigate further the possible facilitatory effects of MB observed in Experiment 1. Previous work in this laboratory (Gold \& van Buskirk, 1975) has shown that using a weak footshock, in this case $500 \mu \mathrm{A}(.5 \mathrm{sec})$, with rats is a particularly effective procedure for demonstrating retrograde enhancement of learning primarily because of low variability in the distribution of retention scores. Because of this, we decided to use rats in the following studies. In this experiment, one of several low doses of MB $(.01, .1,1.0 \mathrm{mg} / \mathrm{kg})$ or saline were given to different groups ( $n=15$ per group) of rats immediately following training. A retention test was given $24 \mathrm{~h}$ after training.

\section{Results}

Table 1 shows the effects of immediate posttrial administration of $\mathrm{MB}$ on retention performance. Analysis of the retention scores (Mann-Whitney U test) indicated that $1.0 \mathrm{mg} / \mathrm{kg}$ MB produced a slight, but 
Table 1

Effect of Immediate Posttrial Administration of Methylene Blue on Retention Performance

\begin{tabular}{lcccc}
\hline & & \multicolumn{3}{c}{ Retention Latency } \\
\cline { 3 - 4 } & Dose & Median & Mean & U \\
\hline \multirow{2}{*}{$\mathrm{NaCl}$} & 9.0 & 2.5 & 4.79 & \\
& .01 & 5.8 & 47.04 & 72.5 \\
Methylene Blue & .10 & 2.9 & 7.82 & 88.0 \\
& 1.00 & 4.4 & 95.05 & $61.0^{*}$ \\
\hline
\end{tabular}

Note-Retention latency values are given in seconds; dose is shown in $\mathrm{mg} / \mathrm{kg}$. $U$ values are based on $U$ test as compared to saline controls. $\quad n=15$ per group. ${ }^{*} p<.05$

significant, retrograde enhancement of learning. However, the other two doses of MB did not affect retention. Inspection of Table 1 will reveal that, in general, the distribution of retention scores of animals that received $1.0 \mathrm{mg} / \mathrm{kg} \mathrm{MB}$ are elevated above those that received saline, as reflected in the medians and the significant $U$ test. The great difference between the median and mean of the rats that received $1.0 \mathrm{mg} / \mathrm{kg} \mathrm{MB}$ indicates that the distribution is highly skewed. Thus, a few animals were greatly affected by administration of $\mathrm{MB}$ and had ceiling retention latency scores.

\section{EXPERIMENT 4}

Following the demonstration that $1.0 \mathrm{mg} / \mathrm{kg} \mathrm{MB}$ produced retrograde enhancement of learning, it was necessary to investigate the effect of time of administration, in order to determine whether MB affects memory consolidation in a time-dependent manner (McGaugh, 1966). Only the $1.0-\mathrm{mg} / \mathrm{kg}$ dose was used in this experiment since the results of Experiment 3 had indicated that the other doses were ineffective. Therefore, either $1.0 \mathrm{mg} / \mathrm{kg} \mathrm{MB}$ or saline was given to rats either $15 \min (M B: n=16$; saline: $n=15$ ) before or $6 \mathrm{~h}$ (MB: $n=16$; saline: $n=15$ ) following training. In addition, a final condition was run to determine whether MB given in close temporal proximity to the retention test would facilitate performance. Two groups of rats received either saline $(n=16)$ or $M B(n=14) 15 \mathrm{~min}$ before the retention test and two additional groups received saline immediately following training and an additional injection of either saline (SALSAL: $n=13$ ) or MB (SAL-MB: $n=15$ ) $15 \mathrm{~min}$ before the retention test. All other training and testing procedures were identical to those of Experiment 3.

\section{Results}

A comparison of the rats that received $1.0 \mathrm{mg} / \mathrm{kg}$ MB to their saline control group indicated that MB was without effect if administered either $15 \mathrm{~min}$ before $[\mathrm{U}(15,15)=82.0, \mathrm{p}>.05] \quad$ or $6 \mathrm{~h}$ after training $[\mathrm{U}(15,15)=108.0, \mathrm{p}>.05]$. The median retention latencies for the four groups were: $15 \mathrm{~min}$ pretrial, saline
$=35.9,1.0 \mathrm{mg} / \mathrm{kg} \mathrm{MB}=11.3 ; 6 \mathrm{~h}$ posttrial, saline $=15.0$, $1.0 \mathrm{mg} / \mathrm{kg} \mathrm{MB}=35.0$.

In the final condition of this study, a comparison of the SAL and MB rats that received only one injection $15 \mathrm{~min}$ prior to the retention test $[\mathrm{U}(14,16)=97.5$, $\mathrm{p}>.05]$ and a comparison of the SAL-SAL vs. SAL-MB groups that received an injection both immediately following training and $15 \mathrm{~min}$ prior to the retention test $[U(13,15)=119.5, p>.05]$ indicated that there was no significant effect of $\mathrm{MB}$ on retention performance. The median retention latencies for these four groups were: (1) $\mathrm{SAL}=4.5$, (2) $\mathrm{MB}=8.3$, (3) SAL-SAL $=13.3$, and (4) SAL-MB $=12.3$.

The animals that received either one injection or two injections were then pooled to evaluate the effects of injections on retention performance. The results indicated that the rats that received two injections (median $=12.8$ ) performed significantly better than the rats that received only one injection (median $=5.45$ ) $(\mathrm{U}=272.5, \mathrm{z}=2.29, \mathrm{p}=.022)$.

\section{DISCUSSION}

The results indicate that $50.0 \mathrm{mg} / \mathrm{kg}$ MB given to mice $15 \mathrm{~min}$, but not 30 or $5 \mathrm{~min}$, prior to training produces an anterograde amnesia in an inhibitory avoidance task. The observed amnesia is probably not due to any general debilitating effect of the drug, since the initial step-through latencies of the MB-treated mice did not differ from the saline control animals. For example, if MB made the mice sick, it might be expected that the animals that received high doses of MB would have longer initial entrance latencies.

A possible explanation for the observed anterograde amnesia in mice is that $\mathrm{MB}$ produces high levels of $\mathrm{MHb}$, reducing the oxygen-carrying capacity of erythrocytes producing hypoxia (Harvey, 1975). It is well known that hypoxia is an effective means of producing a retention deficit of an inhibitory avoidance response (Anderson \& Robichaud, 1975). However, before this conclusion can be accepted with any certainty, it must be demonstrated that the production of $\mathrm{MHb}$ by $\mathrm{MB}$ correlates with the observed results, and since pretrial administration of $\mathrm{MB}$ affected acquisition of the response, proactive effects of $\mathrm{MB}$ on sensory, motivational, or attentional variables cannot be ruled out. The finding that MB produces amnesia only if it is given $15 \mathrm{~min}$ before but not $5 \mathrm{~min}$ after training would explain why MB did not produce retrograde amnesia.

Interestingly, in rats, a small dose of $\mathrm{MB}$ produced a significant retrograde enhancement of learning when a weak footshock was employed, although the magnitude of the observed difference was small (see Table 1). It is important to note that the drug was administered after training, and could not have interfered with acquisition of the response, but acted in a retrograde manner to enhance retention $24 \mathrm{~h}$ later, indicating that it acted 
on some aspect of short-term memory (McGaugh \& Herz, 1972). Moreover, Experiment 4 demonstrated that the effect is time-dependent (McGaugh, 1966) and that $1.0 \mathrm{mg} / \mathrm{kg}$ of $\mathrm{MB}$ does not facilitate performance or promote retrieval of memory (Spear, 1973) if it is given in close temporal proximity to the retention test. If the drug had some nonspecific effect on arousal or general activity, then it would be expected that the MB administered $15 \mathrm{~min}$ before, $6 \mathrm{~h}$ after the training experience, or $1 \mathrm{~h}$ before the retention test would have had a facilitating effect as well. This was not the case. The fact that animals that received two injections had significantly longer latencies than those that received only one injection suggests that injections may be punishing or arousing even though the observed retention scores were very low. Therefore, studies that utilize a retrieval design should evaluate the effects of injections themselves on retention performance.

The action of small doses of MB on memory processes in rats is rather unique, since there is no enhancement of learning if it is given before training, at least under the experimental conditions used in this study. This suggests that the amnestic (high doses) and enhancing (low doses) properties of MB are mediated by different mechanisms, since the temporal characteristics and the direction of the behavioral results obtained with high and low doses are quite different, if rats and mice may be compared in this situation. This would agree with the fact that MB has distinct effects on blood hemoglobin and glucose oxidation, depending on dose (Harvey, 1975; Smith \& Thron, 1972). However, it is the unusual enhancing property of MB that makes it of particular interest for hypotheses concerning memory consolidation (McGaugh, 1973; McGaugh \& Herz, 1972). The observed retrograde enhancement of leaming might be due to the action of MB on NADPH (Smith \& Thron, 1972), to reductions in the normal content of $\mathrm{MHb}$ and the resultant increase in the oxygen carrying capacity of erythrocytes (Harvey, 1975), or both. Since the normal amount of $\mathrm{MHb}$ in rats varies only between $1 \%$ and $3 \%$ of total $\mathrm{Hb}$, it seems unlikely that this con- tributed significantly to the effect. However, this possibility cannot be ruled out on the basis of the present evidence. The most important implication of the present results is that manipulation of the pentose phosphate pathway may act to modulate memory storage processes.

\section{REFERENCES}

Anderson, J. E., \& Robichaud, R. C. Retrograde amnesia induced by hypoxia and electroconvulsive shock in two rat strains. Physiology \& Behavior, 1975, 14, 81-84.

Gold, P. E., \& VAN BUSKIRK, R. B. Facilitation of time-dependent memory processes with posttrial epinephrine injections. Behavioral Biology, 1975, 13, 145-153.

HARVEY, S. C. Antiseptics and disinfectants; ectoparasiticides. In L. S. Goodman \& A. Gilman (Eds.), The pharmacological basis of therapeutics. New York: MacMillan, 1975.

HAYcock, J. W., \& McGAUGH, J. L. Retrograde amnesia gradients as a function of ECS-intensity. Behavioral Biology, 1973, 9, 123-127.

Hiмwich, W. A. Cerebral metabolism during growth of mammals. In H. E. Himwich (Ed.), Brain metabolism and cerebral disorders. New York: Spectrum, 1976.

JARVIK, M. E., \& KoPP, R. An improved one- trial passive avoidance learning situation. Psychological Reports, 1967, 21, 221-224.

MAKer, H. S., Clarke, D. D., \& LAJtha, A. L. Intermediary metabolism of carbohydrates and amino acids. In G. J. Siegel, R. W. Albers, R. Katzman, \& B. W. Agranoff (Eds.), Basic neurochemistry. Boston: Little, Brown, 1976.

Martinez, JR., J. L., McGaugh, J. L., Hanes, C. L., \& LACOB, J. S. Modulation of memory processes induced by stimulation of the entorhinal cortex. Physiology \& Behavior, 1977, 19, 139-144.

McGaugh, J. L. Time-dependent processes in memory storage. Science, 1966, 153, 1351-1358.

McGaugh, J. L. Drug facilitation of learning and memory. Annual Review of Pharmacology, 1973, 13, 229-241.

McGaugh, J. L., \& Herz, M. J. Memory consolidation. San Francisco: Albion, 1972.

SMith, R. P., \& Thron, C. D. Hemoglobin, methylene blue and oxygen interactions in human red cells. Journal of Pharmacology and Experimental Therapeutrics, 1972, 183, 549-558.

SPEAR, N. E. Retrieval of memory in animals. Psychological Review, 1973, 80, 163-194.

(Received for publication February 3, 1978; revision accepted April 10, 1978.) 